\title{
Road Traffic Accidents in Saudi Arabia: An ARDL Approach and Multivariate Granger Causality
}

\author{
Mohammed Moosa Ageli ${ }^{1}$ \& Amal Mousa Zaidan ${ }^{2}$ \\ ${ }^{1}$ King Saud University, Riyadh, Saudi Arabia \\ ${ }^{2}$ College of Public Health and Health Informatics, King Saud Bin Abdulaziz University for Health Sciences, \\ Riyadh, Saudi Arabia \\ Correspondence: Mohammed Moosa Ageli, Assistant Professor of Economics, King Saud University, Riyadh, \\ Saudi Arabia. E-mail: mageli@ksu.edu.sa
}

Received: April 24, 2013

Accepted: June 3, 2013

Online Published: June 20, 2013

doi:10.5539/ijef.v5n7p26

URL: http://dx.doi.org/10.5539/ijef.v5n7p26

\begin{abstract}
The present paper examine the nexus between road traffic accident (RTA) and some relevant variables in Saudi Arabia over the period 1971- 2012, using the autoregressive distributed lag ARDL model (Pesaran and Shin, 1999) for co-integration in Saudi Arabia, with the co-integration test. Results show that the variables are co-integrated in Saudi Arabia, moreover, the overall Granger causality results present that road traffic accidents, population and GDP, road mails, registered vehicles, and the number of driver license are Granger-causes each other in Saudi Arabia. With these findings, we affirm that there is a strong relationship and effect between road traffic accidents and its population, GDP, road mails, registered vehicles, and the number of driver license. The findings suggest that the $E C T_{t-1}$ coefficients are negative signed and statistically significant in all VECMs, implying that there is bi-directional causality between the variables of interest in the long run.
\end{abstract}

Keywords: road traffic accident, Granger Causality, (ARDL) model, Co-integration test, Saudi Arabia

\section{Introduction}

Road Traffic Accidents (RTAs) are a major public health problem. The worldwide incidence of RTAs had caused 1.24 million deaths, 20 to 50 million non-fatal injuries, and many permanent disabilities (WHO, 2013). RTAs ranked as the ninth cause of disability adjusted life years (DALY) lost and they are estimated to rise by a third by 2020 .

In 2013, WHO estimated the road traffic death rate per 100,000 populations to be $24.6 \%$. According to the Director General Directorate of Traffic, the number traffic accidents during 2011 increased to reach more than 544,000 accidents. This incidence resulted in more than 39,000 injuries and 7,153 deaths, $75 \%$ of which were young people. Moreover, RTAs loss accounted for more than $80 \%$ of the death in the Ministry of Health hospitals, and 7 billion losses in the economy each year (WHO and Saudi Arabia, 2006-2013).

Generally, road traffic victims occupy a fifth of the Ministry of Health hospital in Saudi Arabia. The majority of them require long-term rehabilitation as a result of disability. RTA causes vary-among them are human-related causes, such as speeding (a factor in $65 \%$ of accidents), driver errors (a factor in $80 \%$ of accidents), and violation of signals at intersections (a factor in 50\% of accidents). Other causes are related to vehicles, the road, and the environment (e.g., road layouts, which contribute to $20 \%$ of accidents) (Al-Naami. et al, 2010). This alarming RTA rate causes a variety of consequences. The physical, psychological and economic consequences affect the victims, families, and communities.

The vast improvement in socioeconomic statues along with the population growth, have contributed to the high number of cars in the roads. This high number of other human related, or non-human related factors had clustered and results in the gradual increment of the total RTAs number that causes the high burden of injuries, disabilities, and deaths during the period of 1971-2012 in Saudi Arabia (Figure 1).

The rest of this study is organised as follows. Section 2 sets out the data and estimation procedures used in this study. Sections 3 present the methodology of (ARDL) model and results, and perform unit root tests and F- test to confirm the co-integration vectors among the variables under study and Granger Causality test. Section 4 discusses the empirical results and lastly, section 5 reports the conclusion. 


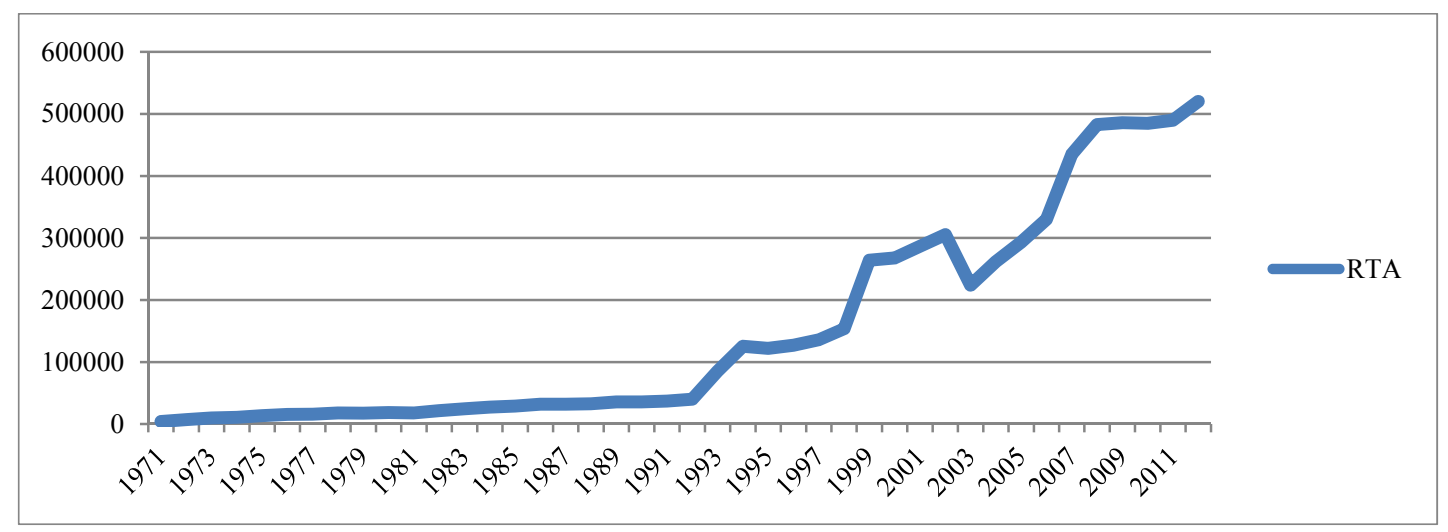

Figure 1. The trend of road traffic accident 1971- 2012

\section{Data and Model}

This study uses the secondary annual data RTA, which measures the Road Traffic Accidents, and used Gross Domestic Product (GDP); POP, which is Population; RM, which is a measure of Road Mails; RV, which is a measure of Registered Vehicles; and NDRL, which is a measure of the Number of Driver Licenses. This paper covers the sample period from 1971 to 2012. All data are collected from the Saudi Arabia Monetary Agency (SAMA), The Ministry of Economy and Planning, The Ministry of Health (MOH), and The Ministry of the Interior police report. All series are transformed into natural logarithm form to obtain stationarity. To test the nexus relationship between the road traffic accident and other variables, we use the following specification model:

$$
\ln R T A_{t}=a_{0}+\pi_{1} \ln R T A_{t-1}+\pi_{2} \ln G D P_{t-1}+\pi_{3} \ln P O P_{t-1}+\pi_{4} \ln R M_{t-1}+\pi_{5} \ln R V_{t-1}+\pi_{6} \ln N D R L_{t-1}+e_{1 t}
$$

The data used in this study consist of the following variables (table 1).

Table 1. Variables definitions

\begin{tabular}{ll}
\hline Variable & Definition \\
\hline The symbol (LN) & Natural Logarithm \\
RTA & Road Traffic Accident \\
GDP & Gross Domestic Product \\
POP & Population \\
RM & Road Mails \\
RV & Registered Vehicles \\
NDRL & Number of Driver Licenses \\
\hline
\end{tabular}

\section{Econometric Estimation Procedures}

\subsection{Unit Root Test}

We applied the Augmented Dickey-Fuller (ADF) (Dickey and Fuller, 1979: 1981), Phillips-Perron (PP) and Kwaitkowski-Phillips-Schmidt-Shin (KPSS) unit root tests to determine the order of integration for each series. Since the ADF test is low power in a small sample (Cheung and Lai, 1995), we also applied the PP and KPSS unit root tests to check the robustness of the estimation results.

\subsection{Cointegration Test}

In next step, we employ the bounds testing approach to co-integration within the autoregressive distributed lag (ARDL) framework (Toda and Yamamoto, 1995) to investigate the existence of a long-run equilibrium relationship between the variables of interest (Pesaran et al., 2001). The bounds testing approach has certain advantages over the conventional co-integration techniques. Unlike the conventional co-integration techniques, the bounds testing approach can be applied to the model irrespective of whether the variables are purely $I(0)$ or purely $I(1)$. In addition to that, the ARDL co-integration approach has superior properties in a small sample (Pesaran and Shin, 1999). The ARDL model for bounds testing approach to co-integration can be formulated as follows: 


$$
\begin{aligned}
& \Delta \ln R T A_{t}=a_{0}+\pi_{1} \ln R T A_{t-1}+\pi_{2} \ln G D P_{t-1}+\pi_{3} \ln P O P_{t-1}+\pi_{4} \ln R M_{t-1}+\pi_{5} \ln R V_{t-1}+\pi_{6} \ln N D R L_{t-1} \\
& +\sum_{j=1}^{k} b_{1 j} \Delta \ln R T A_{t-j}+\sum_{j=0}^{k} b_{2 j} \Delta \ln G D P_{t-j}+\sum_{j=0}^{k} b_{3 j} \Delta \ln P O P_{t-j}+\sum_{j=0}^{k} b_{4 j} \Delta \ln R M_{t-j}+\sum_{j=0}^{k} b_{5 j} \Delta \ln R V_{t-j}+\sum_{j=0}^{k} b_{6 j} \Delta \ln N D R L_{t-j}+e_{1 t} \\
& \Delta \ln G D P_{t}=a_{0}+\pi_{1} \ln G D P_{t-1}+\pi_{2} \ln R T A_{t-1}+\pi_{3} \ln P O P_{t-1}+\pi_{4} \ln R M_{t-1}+\pi_{5} \ln R V_{t-1}+\pi_{6} \ln N D R L_{t-1} \\
& +\sum_{j=1}^{k} b_{1 j} \Delta \ln G D P_{t-j}+\sum_{j=0}^{k} b_{2 j} \Delta \ln R T A_{t-j}+\sum_{j=0}^{k} b_{3 j} \Delta \ln P O P_{t-j}+\sum_{j=0}^{k} b_{4 j} \Delta \ln R M_{t-j}+\sum_{j=0}^{k} b_{5 j} \Delta \ln R V_{t-j}+\sum_{j=0}^{k} b_{6 j} \Delta \ln N D R L_{t-j}+e_{1 t} \\
& \Delta \ln P O P_{t}=a_{0}+\pi_{1} \ln P O P_{t-1}+\pi_{2} \ln R T A_{t-1}+\pi_{3} \ln G D P_{t-1}+\pi_{4} \ln R M_{t-1}+\pi_{5} \ln R V_{t-1}+\pi_{6} \ln N D R L_{t-1} \\
& +\sum_{j=1}^{k} b_{1 j} \Delta \ln P O P_{t-j}+\sum_{j=0}^{k} b_{2 j} \Delta \ln R T A_{t-j}+\sum_{j=0}^{k} b_{3 j} \Delta \ln G D P_{t-j}+\sum_{j=0}^{k} b_{4 j} \Delta \ln R M_{t-j}+\sum_{j=0}^{k} b_{5 j} \Delta \ln R V_{t-j}+\sum_{j=0}^{k} b_{6 j} \Delta \ln N D R L_{t-j}+e_{1 t} \\
& \Delta \ln R M_{t}=a_{0}+\pi_{1} \ln R M_{t-1}+\pi_{2} \ln R T A_{t-1}+\pi_{3} \ln G D P_{t-1}+\pi_{4} \ln P O P_{t-1}+\pi_{5} \ln R V_{t-1}+\pi_{6} \ln N D R L_{t-1} \\
& +\sum_{j=1}^{k} b_{1 j} \Delta \ln R M_{t-j}+\sum_{j=0}^{k} b_{2 j} \Delta \ln R T A_{t-j}+\sum_{j=0}^{k} b_{3 j} \Delta \ln G D P_{t-j}+\sum_{j=0}^{k} b_{4 j} \Delta \ln P O P_{t-j}+\sum_{j=0}^{k} b_{5 j} \Delta \ln R V_{t-j}+\sum_{j=0}^{k} b_{6 j} \Delta \ln N D R L_{t-j}+e_{1 t} \\
& \Delta \ln R V_{t}=a_{0}+\pi_{1} \ln R V_{t-1}+\pi_{2} \ln R T A_{t-1}+\pi_{3} \ln G D P_{t-1}+\pi_{4} \ln P O P_{t-1}+\pi_{5} \ln R M_{t-1}+\pi_{6} \ln N D R L_{t-1} \\
& +\sum_{j=1}^{k} b_{1 j} \Delta \ln R V_{t-j}+\sum_{j=0}^{k} b_{2 j} \Delta \ln R T A_{t-j}+\sum_{j=0}^{k} b_{3 j} \Delta \ln G D P_{t-j}+\sum_{j=0}^{k} b_{4 j} \Delta \ln P O P_{t-j}+\sum_{j=0}^{k} b_{5 j} \Delta \ln R M_{t-j}+\sum_{j=0}^{k} b_{6 j} \Delta \ln N D R L_{t-j}+e_{1 t} \\
& \Delta \ln N D R T L_{t}=a_{0}+\pi_{1} \ln N D R T L_{t-1}+\pi_{2} \ln R T A_{t-1}+\pi_{3} \ln G D P_{t-1}+\pi_{4} \ln P O P_{t-1}+\pi_{5} \ln R M_{t-1}+\pi_{6} \ln R V_{t-1} \\
& +\sum_{j=1}^{k} b_{1 j} \Delta \ln N D R L_{t-j}+\sum_{j=0}^{k} b_{2 j} \Delta \ln R T A_{t-j}+\sum_{j=0}^{k} b_{3 j} \Delta \ln G D P_{t-j}+\sum_{j=0}^{k} b_{4 j} \Delta \ln P O P_{t-j}+\sum_{j=0}^{k} b_{5 j} \Delta \ln R M_{t-j}+\sum_{j=0}^{k} b_{6 j} \Delta \ln R V_{t-j}+e_{1 t}
\end{aligned}
$$

were:

- $\Delta$ is the first difference operator,

- (ln) denotes the natural logarithm,

- $k$ is the lag order selected by Akaike's Information Criterion (AIC).

$\ln R T A_{t}, \ln G D P_{t}, \ln P O P_{t}, \ln R M_{t}, \ln R V_{t}$ and $\ln N D R L_{t}$ are Road Traffic Accidents, real GDP, Total Population, Road Mails, Registered Vehicles and the Number of Driver Licenses, respectively. The residuals $e_{i t}$ are assumed to be normally distributed and white noise. According to Pesaran et al. (2001), we can use the F-test (Turner, 2006) to determine the presence of a long-run relationship by restricting the coefficients of the lagged level variables $\left(H_{0}: \pi_{1}=\pi_{2}=\pi_{3}=\pi_{4}=\pi_{5}=\pi_{6}=0\right)$ from equations (1) to (6). Pesaran et al. (2001) computed the sets of asymptotic critical values for the ARDL co-integration test that is lower bounds critical values $I(0)$ and upper bounds critical values $I(1)$. The critical values tabulated in Pesaran et al. (2001) are not suitable for small sample study, in order to circumvent this problem, Narayan (2005) provided a new set of critical values for small sample. Given the sample size of our study are only 42 observations; we employ the critical values suggested by Narayan (2005) instead of Pesaran et al. (2001).

If the calculated F-statistics exceeds the upper bound critical value, we conclude in favour of a long-run relationship regardless of the order of integration. If the calculated F-statistics falls below the lower critical values, we cannot reject the null hypothesis of no co-integration. However, if the calculated F-statistic falls between the two critical bounds, inference would be inconclusive.

\subsection{Granger Causality Test}

Regarding to, Granger causality, ' $X$ causes $Y$ ' if and only if the past values of $X$ help to predict the changes of $Y$. While, ' $Y$ causes $X$ ' if and only if the past values of $Y$ help to predict the changes of $X$ (Granger, 1988). The Vector Auto Regression (VAR) model is likely to be used for this purpose. However, Granger (1988) noted that if sets of variables are co-integrated, there must be short- and long-run causality, which cannot be captured by the standard first difference VAR model. In this case, we must implement the Granger causality test with the VECM framework as follows:

$$
\Delta \ln R T A_{t}=\alpha_{1}+\sum_{i=1}^{p} \beta_{i} \Delta \ln R T A_{t-i}+\sum_{i=1}^{p} \vartheta_{i} \Delta \ln G D P_{t-i}+\sum_{i=1}^{p} \kappa_{i} \Delta \ln P O P_{t-i}+\sum_{i=1}^{p} \theta_{i} \Delta \ln R M_{t-i}+\sum_{i=1}^{p} f_{i} \Delta \ln R V_{t-i}+\sum_{i=1}^{p} d_{i} \Delta \ln N D R L_{t-i}+\psi_{1} E C T_{t-1}+v_{t}
$$




$$
\begin{aligned}
& \Delta \ln G D P_{t}=\alpha_{1}+\sum_{i=1}^{p} \beta_{i} \Delta \ln G D P_{t-i}+\sum_{i=1}^{p} \vartheta_{i} \Delta \ln R T A_{t-i}+\sum_{i=1}^{p} \kappa_{i} \Delta \ln P O P_{t-i}+\sum_{i=1}^{p} \theta_{i} \Delta \ln R M_{t-i}+\sum_{i=1}^{p} f_{i} \Delta \ln R V_{t-i}+\sum_{i=1}^{p} d_{i} \Delta \ln N D R L_{t-i}+\psi_{1} E C T_{t-1}+v \\
& \Delta \ln P O P_{t}=\alpha_{1}+\sum_{i=1}^{p} \beta_{i} \Delta \ln P O P_{t-i}+\sum_{i=1}^{p} \vartheta_{i} \Delta \ln R T A_{t-i}+\sum_{i=1}^{p} \kappa_{i} \Delta \ln G D P_{t-i}+\sum_{i=1}^{p} \theta_{i} \Delta \ln R M_{t-i}+\sum_{i=1}^{p} f_{i} \Delta \ln R V_{t-i}+\sum_{i=1}^{p} d_{i} \Delta \ln N D R L_{t-i}+\psi_{1} E C T_{t-1}+v \\
& \Delta \ln R M_{t}=\alpha_{1}+\sum_{i=1}^{p} \beta_{i} \Delta \ln R M_{t-i}+\sum_{i=1}^{p} \vartheta_{i} \Delta \ln R T A_{t-i}+\sum_{i=1}^{p} \kappa_{i} \Delta \ln G D P_{t-i}+\sum_{i=1}^{p} \theta_{i} \Delta \ln P O P_{t-i}+\sum_{i=1}^{p} f_{i} \Delta \ln R V_{t-i}+\sum_{i=1}^{p} d_{i} \Delta \ln N D R L_{t-i}+\psi_{1} E C T_{t-1}+v \\
& \Delta \ln R V_{t}=\alpha_{1}+\sum_{i=1}^{p} \beta_{i} \Delta \ln R V_{t-i}+\sum_{i=1}^{p} \vartheta_{i} \Delta \ln R T A_{t-i}+\sum_{i=1}^{p} \kappa_{i} \Delta \ln G D P_{t-i}+\sum_{i=1}^{p} \theta_{i} \Delta \ln P O P_{t-i}+\sum_{i=1}^{p} f_{i} \Delta \ln R M_{t-i}+\sum_{i=1}^{p} d_{i} \Delta \ln N D R L_{t-i}+\psi \\
& \Delta \ln N D R L_{t}=\alpha_{1}+\sum_{i=1}^{p} \beta_{i} \Delta \ln N D R L_{t-i}+\sum_{i=1}^{p} \vartheta_{i} \Delta \ln R T A_{t-i}+\sum_{i=1}^{p} \kappa_{i} \Delta \ln G D P_{t-i}+\sum_{i=1}^{p} \theta_{i} \Delta \ln P O P_{t-i}+\sum_{i=1}^{p} f_{i} \Delta \ln R M_{t-i}+\sum_{i=1}^{p} d_{i} \Delta \ln R V_{t-i}+\psi
\end{aligned}
$$

where $\Delta$ is the first difference operator and $\ln$ is the natural logarithm. The residuals $v_{t}$ are assumed to be normally distributed and white noise. $E C T_{t-1}$ is one period lagged error-correction term derived from the co-integration equation.

\section{Empirical Results}

In this section, we begin by testing the order of integration using ADF, PP and KPSS unit root tests. The results of the three unit root tests are reported in Table 2. At the 1 per cent significant level, the results of ADF unit root test suggest that all variables are integrated of order one, I(1) process. However, the PP and KPSS unit root tests exhibit that all variables included population are stationary at the first difference. As noted in the earlier section, the ADF test often has weak power when the sample size of a study is small, so we preferred to use the results provided by PP and KPSS unit root tests. For this reason, we surmised that the variables can be well characterised as $I(1)$ process.

Table 2. Unit root estimation

\begin{tabular}{lllllll}
\hline Variables & ADF $(0)$ & ADF $(1)$ & PP $(0)$ & PP $(1)$ & KPSS $(0)$ & KPSS (1) \\
\hline LNGDP & -2.036 & -5.106 & -2.576 & -9.330 & 0.170 & 0.052 \\
LNRTA & -3.173 & -4.901 & -3.063 & -3.997 & 0.243 & 0.060 \\
LNPOP & -7.200 & -4.361 & -1.837 & -6.263 & 0.162 & 0.067 \\
LNRM & -1.833 & -4.410 & -0.999 & -4.455 & 0.232 & 0.099 \\
LNRV & -3.001 & -4.625 & -2.698 & -5.422 & 0.120 & 0.052 \\
LNNDRL & -3.751 & -4.177 & -3.021 & -3.986 & 0.217 & 0.083 \\
\hline
\end{tabular}

Given that all variables are integrated of order one, we proceed to examine whether road traffic accidents, GDP, population, road mails, road vehicles and the number of driver licenses are co-integrated using the bounds testing approach to co-integration. An important issue in applying bounds testing approach to co-integration is the selection of optimal lag length. In this paper, we set the maximum lag length at 3 years which is sufficiently long for annual data study to capture the dynamic relationship, then the AIC statistic is use to choose the best ARDL models. AIC statistics is preferred in this study because it has superior properties, particularly in a small sample (Lütkepohl, 2005). The calculated F-statistics for co-integration together with the diagnostic tests are reported in Table 3 .

In all cases, the calculated F-statistics are greater than the 1\% upper bound critical values provided by Narayan (2005). Therefore, the null hypothesis of no co-integration can be rejected, implying that a long-run equilibrium relationship exists between road traffic accidents, GDP, population, road mails, road vehicles and the number of driver licenses in Saudi Arabia.

After determining the presence of co-integration, it is also interesting to perform the Granger causality test to understanding the direction of causality. As the variables are co-integrated, we employed the Granger causality in the VECM framework to determine the direction of causality between the variables. The results of Granger causality are presented in Table 4 . Since the variables are co-integrated, the direction of causality can be divided into short- and long-run causation. Begin with the long-run causality, our empirical results suggest that the $E C T_{t-1}$ coefficients are negative signed and statistically significant in all VECMs, implying that there is bi-directional causality between the variables of interest in the long run. 
Table 3. The results of ARDL co-integration test

\begin{tabular}{llll}
\hline Bounds testing to cointegration & & & \\
\hline & Optimal lag length & F-statistics & $\chi_{N O R M A L}^{2}$ \\
\hline$F_{R T A}(R T A \mid G D P, P O P, R M, R V, N D R L)$ & $1,2,1,1,0$ & 7.462 & 0.591 \\
$F_{G D P}(G D P \mid R T A, P O P, R M, R V, N D R L)$ & $1,1,3,2,3$ & 11.271 & 1.431 \\
$F_{P O P}(P O P \mid R T A, G D P, R M, R V, N D R L)$ & $2,2,1,2,0$ & 12.801 & 0.856 \\
$F_{R M}(R M \mid R T A, G D P, P O P, R V, N D R L)$ & $2,2,1,2,1$ & 14.197 & 1.786 \\
$F_{R V}(R V \mid R T A, G D P, P O P, R M, N D R L)$ & $1,0,1,0,3$ & 19.702 & 1.339 \\
$F_{N D R L}(N D R L \mid R T A, G D P, P O P, R M, R V)$ & $1,2,2,1,0$ & 20.751 & 1.871 \\
\hline Significant level & Critical values $(\mathrm{T}=42)^{\#}$ & & \\
\cline { 2 - 2 } & Lower bounds $I(0)$ & Upper bounds $I(1)$ & \\
\hline $1 \%$ & 4.045 & 5.898 & \\
$10 \%$ & 2.962 & 4.268 & \\
\hline
\end{tabular}

Table 4. The results of Granger Causality Test

\begin{tabular}{l|lllllll}
\hline $\begin{array}{l}\text { Dependent } \\
\text { Variables }\end{array}$ & \multicolumn{1}{l}{ Short-run } & \multicolumn{7}{l}{} & Long-run \\
\cline { 2 - 7 } & $\sum \Delta \ln R T A_{t-i}$ & $\sum \Delta \ln G D P_{t-i}$ & $\sum \Delta \ln P O P_{t-i}$ & $\sum \Delta \ln R M_{t-i}$ & $\sum \Delta \ln R V_{t-i} \sum \Delta \ln N D R L_{t-i}$ & $E C T_{t-1}$ \\
\hline$\Delta \ln R T A_{t}$ & - & 30.89 & 14.61 & 10.53 & 7.65 & 11.54 & -0.775 \\
$\Delta \ln G D P_{t}$ & 21.67 & - & 10.75 & 34.75 & 1.71 & 9.11 & -0.798 \\
$\Delta \ln P O P_{t}$ & 0.52 & 0.13 & - & 9.49 & 6.28 & 7.39 & -0.187 \\
$\Delta \ln R M_{t}$ & 14.12 & 42.72 & 0.49 & - & 17.42 & 13.82 & -0.284 \\
$\Delta \ln R V_{t}$ & 18.60 & 9.34 & 13.18 & 5.49 & - & 6.60 & -0.793 \\
$\Delta \ln N D R L_{t}$ & 16.86 & 8.29 & 12.01 & 4.92 & 13.97 & - & -0.704 \\
\hline
\end{tabular}

Contrary with the findings of long-run causality, we find that the short-run causality vary among VECMs. In summary, our empirical evidence shows that at the $1 \%$, there are Granger causality runs from GDP, population, road mails, road vehicles and the number of driver licenses to road traffic accidents. However, at the same level of significance, the results show Granger causality runs from the road traffic accidents to independent variables. With respect to these findings, we affirmed that road traffic accident; GDP, population, road mails, road vehicles and the number of driver licenses are bi-directional causality. These evidences strongly indicate that the variables in the system are dynamically interacted.

\section{Conclusion}

This paper examines the causality relationship between the road traffic accidents (RTA), GDP, population, road mails, road vehicles and the number of driver licenses in Saudi Arabia over period 1971 - 2012, by using a multivariate framework analysis. In order to achieve the objective, we employed the bounds testing to examine the co-integrating relationship between the variables. We applied the Granger causality test within the VECM model to verify the direction of causality between variables. The results show, that the variables are co-integrated, meaning that there is a stable long-run relationship between road traffic accidents and its determinants although there might be deviation in the short-run, found that road traffic accidents and the independent variables is bi-directional causality in Saudi Arabia. Therefore, the Saudi government should encourage economic research and development on the cost and policy for road traffic accidents. Therefore, road traffic accidents are insufficient to promote the economic and medical research and their effect on the economy in Saudi Arabia.

\section{References}

Cheung, Y. W., \& Chinn, M. D. (1997). Further investigation of the uncertain unit root in GNP. Journal of Business and Economic Statistics, 15, 68-73.

Dickey, D. A., \& Fuller, W. A. (1979). Distribution of the Estimators for Autoregressive Time Series with a Unit Root. Journal of the American Statistical Association, 74, 427-431.

Dickey, D. A., \& Fuller, W. A. (1981). Likelihood Ratio Statistics for Autoregressive Time Series with a Unit 
Root. Econometrica, 49, 1057-1072. http://dx.doi.org/10.2307/1912517

Granger, C. W. J. (1980). Testing for Causality. Journal of Economic Dynamics and Control, 2, 329-352. http://dx.doi.org/10.1016/0165-1889(80)90069-X

Granger, C. W. J. (1988). Causality, cointegration, and control. Journal of Economic Dynamics and Control, 12, 551-559. http://dx.doi.org/10.1016/0165-1889(88)90055-3

Kwiatkowski, D., Phillips, P. C. B., Schmidt, P., \& Shin, Y. (1992). Testing the null hypothesis of stationarity against the alternative of a unit root: How sure are we that economic time series have a unit root? Journal of Econometrics, 54, 159-178. http://dx.doi.org/10.1016/0304-4076(92)90104-Y

Lütkepohl, H. (2005). New Introduction to Multiple Time Series Analysis. Springer-Verlag, Berlin. http://dx.doi.org/10.1007/978-3-540-27752-1

Ministry of the Interior, Riyadh. Traffic General Directorate. (2012). Annual Traffic Report.

Pesaran, M. H., \& Shin, Y. (1999). An Autoregressive Distributed-led Modelling Approach to Cointegration Analysis. Cambridge University Press, Cambridge.

Pesaran, M. H., Shin, Y., \& Smith, R. J. (2001). Bounds testing approaches to the analysis of level relationships. Journal of Applied Econometrics, 16, 289-326. http://dx.doi.org/10.1002/jae.616

The Saudi Arabia Monetary Agency (SAMA). (2001 to 2012). Annual Report. SAMA.

Toda, H. Y., \& Yamamoto, T. (1995). Statistical inference in vector autoregressions with possibly integrated processes. Journal of Econometrics, 66, 225-250. http://dx.doi.org/10.1016/0304-4076(94)01616-8

Turner, P. (2006). Response surfaces for an F-test for cointegration. Applied Economics Letters, 13, 479-482. http://dx.doi.org/10.1080/13504850500401726

World Health Organization, (WHO). Country Cooperation Strategy for WHO and Saudi Arabia: (2006-2013).

\section{Copyrights}

Copyright for this article is retained by the author(s), with first publication rights granted to the journal.

This is an open-access article distributed under the terms and conditions of the Creative Commons Attribution license (http://creativecommons.org/licenses/by/3.0/). 